\title{
Interlanguage: A Case Study of English Narrative Discourse of an Indonesian Studying in the U.S.
}

\author{
Stefanus Angga B. Prima \\ stefanus.angga@podomorouniversity.ac.id \\ Universitas Agung Podomoro, Indonesia
}

\begin{abstract}
This study aims to see how an Indonesian studying in the U.S. uses English tense and aspects to produce meaning oral narrative discourses. The Indonesian's verbatim of narrative discourse is compared to that of a Minnesota-born English speaker studying in a university in the midwestern of the United States. The audio-recorded narrative discourses are transcribed, then foregrounding and backgrounding clauses of each participant's oral narrative discourse are analyzed to count the number of verbs produced by each participant. The verbs are categorized into past verbs (simple, progressive, pluperfect) and non-past verbs (base forms, present tense, present progressive, present perfect). By analyzing the morphology distribution, the researcher recorded that the Minnesotan participant used past tense more frequently in foregrounding and backgrounding clauses in both narrative tasks, while the Indonesian used more temporal adverbs than that of the Minnesotan.
\end{abstract}

Keywords: interlanguage, narrative, SLA, tense and aspects

\section{INTRODUCTION}

Varieties of linguistic devices that second language learners use in the context of interlanguage temporality has been long under investigation. Past research studies (Bardovi-Harlig, 1995; Chiravate, 2011; Bardovi-Harlig in Han \& Tarone, 2014) show that it is possible to see how L2 speakers produce meaning using English verbal morphology by asking them to tell a narrative, either oral or written. The current study pursues the same purpose-to examine the use of tense and aspect used by Indonesian speakers of English when making meaning in oral narrative discourse. There are differences in tense/aspect and verb-agreement marking in Indonesian language compared to that of English, and it is interesting to explore to see if L1 transfer occurs during English production. With the notion that depicts learners' interlanguage system as "a system on its own right" (Selinker, 1972), the current study does not try to tell that non-native speaker's system in using verbal morphology in telling a narrative discourse compared to that of targetlike utterances by a native speaker is wrong. This study, however, is capturing how the non-native speaker utilizes various linguistic devices to narrate a story or when she produces meaningful utterances in a natural setting. In addition, I chose to perceive interlanguage data collected in this 
study with concept-oriented approach (Bardovi-Harlig, 2014). With this approach, learner's language that are not 'target-like' are not always considered to be less preferable or something that needs to be fixed.

\section{LITERATURE OF REVIEW}

\section{Tense and Aspect in English and Bahasa Indonesia}

Unlike the English language, which is rich in inflectional morphology to mark tense, aspect, and verb agreement, Bahasa Indonesia or Indonesian language does not possess verb inflection to mark those three elements. In other words, verb inflection for tense, aspect, and the subject-verb agreement does not exist in Indonesian language (Anjarningsih \& Bastiaanse, 2011). Thus, Indonesian verbal predicates look completely different from English which includes inflectional morphology or irregular verb change to mark the tense, aspect, and agreements. The following example taken from Anjarningsih and Bastiaanse (2011) illustrates this further.
1) Azka makan nasi setiap pagi
Azka eat rice every morning
"Azka eats rice every morning"
2) Azka dan Diana makan nasi setiap pagi Azka and Diana eat rice every morning "Azka and Diana eat rice every morning"
3) Azka makan nasi kemarin sore Azka eat rice yesterday afternoon "Azka ate rice yesterday afternoon"

On the other hand, the Indonesian temporal lexical adverbs behave almost syntactically like that of English language. Another excerpt from Anjarningsih and Bastiaanse (p. 1565) shows the similarity.

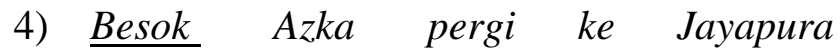

Tomorrow Azka go to Jayapura

"Tomorrow Azka will go to Jayapura"
5) Azka besok pergi ke Jayapura
Azka tomorrow go to Jayapura

"Azka will go to Jayapura tomorrow"
6) Azka pergi ke Jayapura besok
Azka besok pergi ke Jayapura
"Azka will go to Jayapura tomorrow"

The similarity of syntactical behavior in both languages has led the current study to investigate whether L1 transfer occurs during the meaningful production my Indonesian participant. The current study is also trying to figure out whether the Indonesian participant of the current study relies on the temporal lexical adverbs due to its similar use in both languages. 


\section{Foregrounding and Backgrounding in Narrative Structure}

Narrative structure is defined as a text which is told or written by a person and can be either real or fictional events. This text is iterated in a sequential manner (Dahl, 1984, p.116 as cited in Bardovi-Harlig, 1995, p. 265). There are two important elements in a narrative structure that work coherently to tell a sequence of events: the foreground and the background.

The foreground is all actions that create the framework of the discourse. In other words, it creates "the skeletal structure of the discourse," whereas the background provides evaluation or expands the actions mentioned in the foreground (Hopper, 1979, as cited in Bardovi-Harlig, 1995, p. 266). Three important criteria of foreground clauses proposed by Reinhart (1984, p. 801) as cited by BardoviHarlig (1995, p. 266) are (1) temporal continuity; (2) events punctuality; and (3) a report of a completed event. In contrast, the background gives more elaboration or evaluation of the event told in the foreground clauses. Further, Bardovi-Harlig (2000), as quoted in Chiravate (2011) explained the background functions as additional information that gives more details to the foreground.

Exploring how tense/aspect or verbal morphology of past tense is used differently in the foreground and the background clauses in oral narratives produced by the participants of the current study will give a clearer picture of how non-native and native speakers of English produce sequential events using different linguistic resources.

\section{Verbal Morphology in a Narrative Structure}

Several important studies of tense/aspect in a narrative structure have indicated that there is a relationship between narrative structure (its foreground/background) and the use of verbal morphology, especially for past tense verbs. The first important study is the one conducted by Bardovi-Harlig (1995), which compares the distribution of simple past in oral and written narratives produced by different levels of learners. The results show that the use of past tense is more prevalent in foregrounding than in backgrounding. Another study by the same author, (Bardovi-Harlig, 2011 in Han \& Tarone, 2014) also shows that as learners develop their ability to use the appropriate past tense, there will be less use of lexical temporal adverb.

Looking at how previous studies investigate the relationship between narrative discourse and the use of verbal morphology in the paradigm of detecting learners' language in interlanguage hypothesis is the goal of the current study. Furthermore, there has been no research study focusing on how Indonesian speaking English users produce meaning in oral narrative discourse pertaining to the use of verbal morphology in foregrounding and backgrounding. Therefore, in the light of finding the pattern of verbal morphology use in a narrative discourse, the current study will answer the following research questions:

1) What are the differences of tense/aspect used in oral narratives produced by native and non-native speakers of English? 
2) How does the temporal lexical adverbs affect the use of tense/aspect in oral narratives produced by both participants?

\section{METHOD}

To observe the variety of linguistic devices which marks time by different language users, the current study used a frame known as the Discourse Hypothesis (DH) which involves discourse grounding principles. DH was firstly introduced by Bardovi-Harlig (1994a) in a study as quoted by Comajoan (2013, p. 309).

Two participants - a non-native and a native English speaker-were selected for this study. Both participants are female students at a midwestern university in the United States. The non-native is a 29 -year-old Indonesian graduate student who is pursuing a master's in accounting. She was exposed to the extensive use of English prior to coming to the United States in her workplace and has learned English for at least 18 years at school in Indonesia. Her TOEFL iBT score is 100 out of 120, which indicates that she is an advanced user of English as a foreign language. Other than her regular class hours at her university, she works as a graduate assistant in her department. Thus, there is a lot of exposure, input, and opportunity to use English in her daily life with native speakers of American English.

The native speaker participant in this study was 23 years old at the time of data collection. She is enrolled as a student in the Department of English and is pursuing an ESL teaching licensure. She was born in Minnesota and is mostly a monolingual American-English speaker in her daily life. However, she has various levels of knowledge and skill in German, Korean, and Spanish. The Minnesotan born and the Indonesian participants both agreed to be audio-recorded during the data collection. The non-native speaker participant from henceforward will be referred as 'Indonesian participant', whereas I will refer to the American English native speaker as 'the Minnesotan participant'.

The current study took a similar technique of collecting data from previous research conducted by Bardovi-Harlig (1995) in which participants were asked to do two tasks: (1) to retell a movie clip orally, and (2) to tell an unforgettable experience. The movie clip was approximately one minute in length and was taken from a silent movie scene named Modern Times, starring Charlie Chaplin. Each participant was asked to watch the clip once and then retell the clip orally. The second task was not conducted right after the first task concluded. Rather, there was a time gap to do the second task, which is around one week for the Indonesian participant and three weeks for the Minnesotan participant. In this study, both participants decided to share their bad experience with a debit card/ATM breach. 
The data collection for the Indonesian participant was conducted in the campus cafeteria, while the native speaker's data was collected in the university's library. These casual settings encouraged them to be relaxed and to boost spontaneous meaning production. In both tasks, the participants' oral narrative production was recorded using an audio-recorder. After that, all four sets of data were transcribed into Microsoft Word and then were analyzed.

After all sets of data were transcribed, the parts in the transcription which has no narrative element (i.e., chit chat, opinions about the movie) were eliminated. Afterward, the clauses were categorized into foregrounding and backgrounding, and counted the frequency of verbs occurred in the transcriptions. I categorized the verbs into three broad categories of past (simple past, past progressive, pluperfect), non-past (base, present, 0 + progressive, and present perfect), and no verb (e.g., "she mad"), which is based on Bardovi-Harlig (1995). The verb categorization was tricky because there were some 'phonological considerations' that I needed to consider during the coding. In Bardovi-Harlig's study on tense/aspect of oral narratives, in which she laid the basis of the verbs categorization, she excluded all verbs that ended in consonant clusters (e.g., walked through/the, walked to/down, pulled down). However, due to the limitation of data I collected with only two participants, I decided to include all verb phrases (produced by both participants) with consonant clusters as data to be analyzed/coded. I also decided to include all verbs containing consonant clusters that do not produce clear $/ \mathrm{d} /$ or $/ \mathrm{t} / \mathrm{as}$ past simple since generally native speakers also frequently do not produce clear finals $/ \mathrm{d} / \mathrm{or} / \mathrm{t} / \mathrm{in}$ their past tense consonant cluster verbs. The next is general syntactical complexity analysis to calculate the number of words, clauses, temporal lexical adverbs, and conjunctions (or cohesive devices) used by both participants in both tasks. The next focus here is the temporal lexical adverbs frequency used by both participants. The purpose is finding out to what extent the non-native speaker utilizes those adverbs in oral narrative tasks compared to that of the native speaker.

\section{RESULT AND DISCUSSIONS}

The verbs distribution used by both participants in foregrounding and backgrounding clauses in both oral narrative tasks are shown in Table 1 and 2 . The verbs are further categorized into Past (Simple, Past Progressive, Pluperfect), non-past (Base, Present, Present Progressive, Progressive, Present Perfect), and no-verb. The first numbers - the one without parenthesis - are the number of occurrences while the numbers in parentheses show the percentage of each verb's distribution in comparison with the total verbs produced by each participant. 


\section{Foregrounding}

The use of past tense appears to be dominant in foregrounding of Retelling Task. The Indonesian participant uses a total of 31 clauses containing 20 past tenses, nine non-past verbs (containing eight base and one present verbs), and two no verb categories. Meanwhile, the Minnesotan's verbs are more varied with 22 past tense (with four past progressives) and five non-past verbs, which contains four present tense and one present progressive tense. With this number, the comparison of past tense occurrence for Indonesian participant's foregrounding clauses during the retelling task is 0.64 per clause (20/31), while the Minnesotan's is 0.81 per clause (22/27), which is only slightly higher than the Indonesian participant.

In the data of verbs distribution for Personal Narrative task as shown in Table 2, past tense still dominates foregrounding tenses used by both participants. The Indonesian participant produces 16 past and 11 non-past tense verbs, which contains eight base and one present verb. Meanwhile, the Minnesotan has 22 past and five non-past tense verbs. With this number, the occurrence of past tense used by the Indonesian participant is 0.59 per clause (16/27), while for the Minnesotan is 0.93 per clause $(25 / 27)$, which is relatively higher in comparison.

Table 1. Verbal Morphology distribution of Retelling Task

\begin{tabular}{|c|c|c|c|c|}
\hline \multirow{2}{*}{$\begin{array}{l}\text { Morphology } \\
\text { Distribution }\end{array}$} & \multicolumn{2}{|c|}{ Indonesian } & \multicolumn{2}{|c|}{ Minnesotan } \\
\hline & $\begin{array}{l}\text { Foregroundi } \\
n g\end{array}$ & Backgrounding & Foregrounding & Backgrounding \\
\hline \multicolumn{5}{|l|}{ Past } \\
\hline Simple & $20(64.52 \%)$ & $2(25 \%)$ & $18(67 \%)$ & $1(50 \%)$ \\
\hline Past Progressive & 0 & 0 & $4(15 \%)$ & 0 \\
\hline Pluperfect & 0 & 0 & 0 & 0 \\
\hline \multicolumn{5}{|l|}{ Non-Past } \\
\hline Base & $8(25.81 \%)$ & 0 & 0 & 0 \\
\hline Present & $1(3.23 \%)$ & $6(75 \%)$ & $4(15 \%)$ & $1(50 \%)$ \\
\hline Present & 0 & 0 & $1(4 \%)$ & 0 \\
\hline Progressive & & & & \\
\hline Progressive & 0 & 0 & 0 & 0 \\
\hline Present Perfect & 0 & 0 & 0 & 0 \\
\hline No Verb & $2(6.45 \%)$ & 0 & 0 & 0 \\
\hline $\begin{array}{l}\text { TOTAL } \\
\text { VERBS }\end{array}$ & $31(100 \%)$ & $8(100 \%)$ & $27(100 \%)$ & $2(100 \%)$ \\
\hline
\end{tabular}

\section{Backgrounding}

In regards with backgrounding for the Retelling Task, the Indonesian participant only has eight clauses which contain two simple past and six non-past (present tense) verbs, thus making the occurrence of past tense significantly lower than that of the foregrounding clauses. The Minnesotan even has only one clause of past tense and one in non-past, which is present tense. This number shows how 
significantly lower the occurrence of past tense in the backgrounding of the Retelling Task compared to the foregrounding clauses -0.25 per clause $(2 / 28)$ for the Indonesian and 0.5 per clause (1/2) for the Minnesotan.

In the second task, the Personal Narrative, the Indonesian uses five clauses of past tense and ten clauses of non-past (five clauses of each present and present perfect tense). Meanwhile, the Minnesotan uses significantly more past tense in the backgrounding, with 27 clauses of simple past, and ten clauses of non-past (consisting of three base, six presents, and one present tense). Therefore, with the data shown in Table 2, the occurrence rate of past tense in of backgrounding clauses of Personal Narrative Task for the Indonesian is 0.33 per clause (5/15) and 0.73 per clause (27/37) for the Minnesotan. Thus, this calculation signifies how past tense is more dominantly used by the Minnesotan in the backgrounding clauses.

Table 2. Verbal Morphology distribution of personal narrative task

\begin{tabular}{|c|c|c|c|c|}
\hline \multirow{2}{*}{$\begin{array}{l}\text { Morphology } \\
\text { Distribution }\end{array}$} & \multicolumn{2}{|c|}{ Indonesian } & \multicolumn{2}{|c|}{ Minnesotan Participant } \\
\hline & Foregrounding & Backgrounding & Foregrounding & Backgrounding \\
\hline \multicolumn{5}{|l|}{ Past } \\
\hline Simple & $16(59 \%)$ & $5(33.33 \%)$ & $25(93 \%)$ & $27(73 \%)$ \\
\hline Past & 0 & 0 & 0 & 0 \\
\hline \multicolumn{5}{|l|}{ Progressive } \\
\hline Pluperfect & 0 & 0 & 0 & 0 \\
\hline \multicolumn{5}{|l|}{ Non-Past } \\
\hline Base & $9(33 \%)$ & 0 & $1(3.7 \%)$ & $3(8 \%)$ \\
\hline Present & $1(4 \%)$ & $5(33.33 \%)$ & $1(3.7 \%)$ & $6(16 \%)$ \\
\hline Present & 0 & 0 & 0 & 0 \\
\hline Progressive & & & & \\
\hline & 0 & 0 & 0 & 0 \\
\hline Progressive & & & & \\
\hline $\begin{array}{l}\text { Present } \\
\text { Perfect }\end{array}$ & $1(4 \%)$ & $5(33.34 \%)$ & 0 & $1(3 \%)$ \\
\hline No Verb & 0 & 0 & 0 & 0 \\
\hline $\begin{array}{l}\text { TOTAL } \\
\text { VERBS }\end{array}$ & $27(100 \%)$ & $15(100 \%)$ & $27(100 \%)$ & $37(100 \%)$ \\
\hline
\end{tabular}

Furthermore, Figure 1 and 2 show more clearly how the distribution of verb categories differ between the Indonesian and the Minnesotan in percentage without the difference between foregrounding and backgrounding clauses. From these two figures, it is indicated that the Minnesotan's clauses in the Retelling Task are highly dominated by past tense, which is the highest in this study. The two figures also clearly show how the Minnesotan uses more past tense in than the Indonesian in all tasks. One striking finding is how the Indonesian uses more non- 
Prima: Interlanguage: A Case Study of English ...

past verbs in the Personal Narrative Task, while using quite significantly lower frequency of past tense there.

Figure 1. The Indonesian participant's distribution of verbs categories

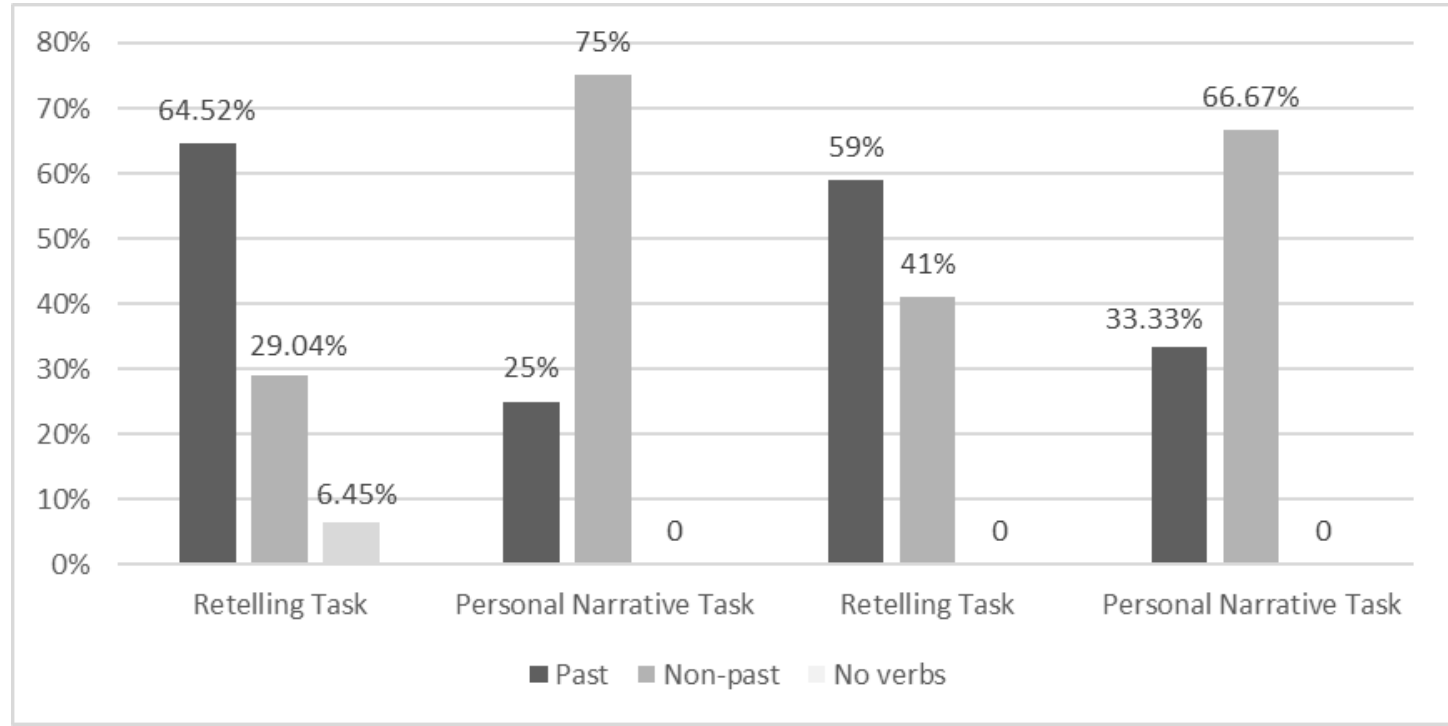

Figure 2. The Minnesotan participant's distribution of verbs categories

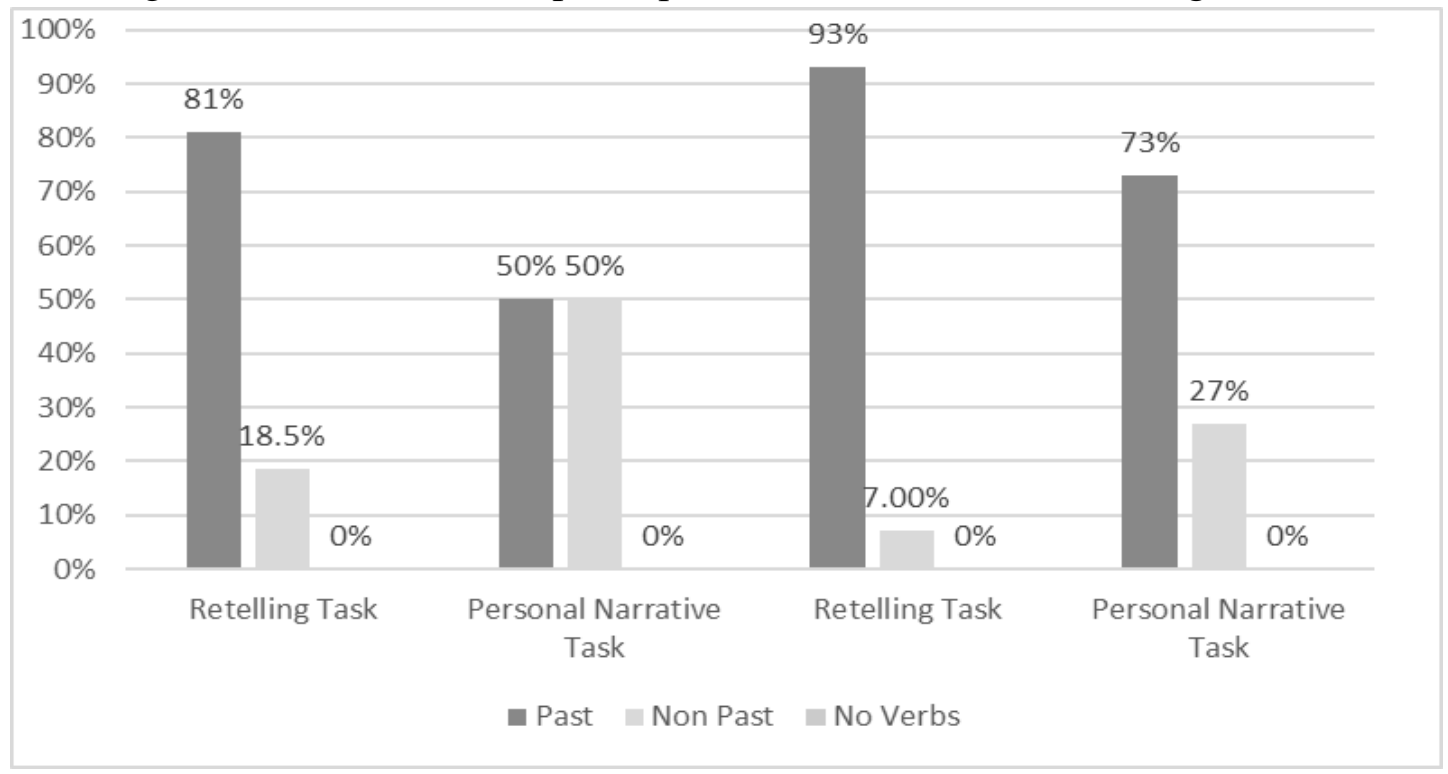

Some examples taken from both participants data are as follows:

(1) Indonesian Participant, Retelling Task, Past tense [6] and first verb in [8], base verbs [7] and the second verb in [8]. 
(2) Foregrounding

[6] And he let the delivery car open

[7] so the woman can, the lady can steal the ... a loaf of bread

[8] Then she ran away with the bread she take mmm... and then

(3) Minnesotan Participant, Retelling Task, Past Progressive.

Foregrounding

[15] Charlie was trying to charm the starving lady by saying like, "No, I took the bread."

(4) Minnesotan Participant, Retelling Task, Past Progressive.

\section{Foregrounding}

[1] So to re-explain the clip... a woman was looking at the bakery window and was thinking how hungry she was.

[2] and the baker was loading from his truck into his shop $u h .$. bread, some sweets and what not.

(5) Indonesian Participant, Retelling Task, No Verb [13], Past Tense [15], [17], [18], [19], [22].

\section{Foregrounding}

[13] and then the guy, the delivery guy mad. ...

[15] and he said, "oh!" ...

[17] and the guy, the delivery guy said to the police, "This lady stole my bread!"

[18] And then the police say, "are you really steal eh stole his bread?"

[19] the lady say, "no... no, I didn't do anything wrong." ...

[22] and said, "No, actually she didn't stole anything. I did. I stole the bread."

\section{Temporal lexical adverbs in both oral narrative tasks}

Table 3 shows the general information of syntactical complexity of both participants in both first and second oral narrative task's transcriptions. It also shows that the Indonesian participant significantly produced more words than the Minnesotan in the first task.

Table 3. General transcription information of oral narrative tasks

\begin{tabular}{|c|c|c|c|c|}
\hline \multirow[b]{2}{*}{ Categories } & \multicolumn{2}{|c|}{ Indonesian } & \multicolumn{2}{|c|}{ Minnesotan } \\
\hline & $\begin{array}{l}\text { Retelling } \\
\text { Task }\end{array}$ & $\begin{array}{l}\text { Personal } \\
\text { Narrative Task }\end{array}$ & $\begin{array}{l}\text { Retelling } \\
\text { Task }\end{array}$ & $\begin{array}{l}\text { Personal } \\
\text { Narrative } \\
\text { Task }\end{array}$ \\
\hline Word counts & 291 & 353 & 182 & 620 \\
\hline Clauses & 33 & 42 & 24 & 30 \\
\hline Direct Sentences & 8 & 7 & 3 & 5 \\
\hline $\begin{array}{ll}\text { Lexical } & \text { temporal } \\
\text { adverb } & \end{array}$ & 4 & 7 & 2 & 2 \\
\hline Conjunctions & 16 & 25 & 9 & 32 \\
\hline
\end{tabular}


Further calculation for the average of lexical temporal adverb occurrence per clause for the Indonesian participant for both tasks resulted in $0.12(4 / 33)$ and 0.16 (7/42) respectively. The Minnesotan participant's average of occurrence per clause for lexical temporal adverbs in both tasks resulted in $0.08(2 / 24)$ and 0.06 $(2 / 30)$.

Also, there was a significant increase of word counts in for the Minnesotan in the personal narrative task from 182 to 620 words. The data in the table also shows that the Indonesian participant considerably produced more lexical temporal adverbs than the Minnesotan in the first task but has the same number of lexical temporal adverbs in the second task although the Indonesian produces fewer words.

\section{The differences of tense/aspect used in oral narratives used by both participants}

The results of the study indicate that when it comes to past tense use, there is no significant difference between the Indonesian participant and the Minnesotan participant. In other words, both participants prefer past simple when telling foregrounding clauses in oral narratives. However, some striking differences occur in both oral narrative tasks.

The first is base verbs. Examples of base verbs produced by the Indonesian participant show that the Indonesian participant still uses modals with base verbs in the foregrounding, which the Minnesotan does not use. The use of verbs is target-language-like, but there is a possibility of divergent meaning than that of the target language, which brings me to concerns about interlanguage data ambiguity (Corder, 1967; Spolsky, 1973 as cited in Selinker, 2014). Further, the use of cohesive device 'so', which comes after line 6, creates an impression that ' $h e$ ' (the baker) intentionally let the woman take a loaf of bread from the bakery truck. This is not the case since the clip clearly showed that 'she' (the female main character) stole the bread because the baker was not aware that someone would steal the bread, and he would go back to take the remaining bread, which is why he kept the truck's door open. Unfortunately, I did not go back to the participant to do a retrospective interview to ask about this sentence. Thus, the use of modals which is followed by a base form 'steal' is the participant's system of interlanguage, which probably does not use past modal form 'could' extensively in referring to past tense. Another base form is shown in line 8. Here, verb 'take' is used similarly to target-like verb agreement for verbs following first or second person in present tense, which interestingly occurs as a relative clause for "the bread'. The main clause itself is in past simple, which occurs after cohesive device 'then'. This may indicate the fact that the Indonesian participant knows how to make meaning use past simple verbs, but it seems that once a past tense verb is used as a morphological indicator of a clause preceding it, she does not keep using past simple. In other words, tense/aspect markedness in her system can be less obvious than that of most native speakers. 


\section{The differences in using the lexical temporal adverbs}

The temporal lexical adverbs look affecting how Indonesian participant uses verb in foregrounding, as shown in the following example, line [16] and [21], where she uses base forms.

\section{Foregrounding}

[15] and he said, "oh!"

[16] and at that time, also the police [20] But yeah, she stole the... my bread come

\section{[21] At that time Charlie Chaplin stand} up for her

[22] and said, "No, actually she didn't stole anything. I did. I stole the bread."

\section{Backgrounding}

In these examples, when producing verbs following a main clause containing past simple verb or another linguistic element tense indicator such as temporal lexical adverbs (i.e., at that time), the Indonesian participant switches the verbal morphology to either base forms several times. One instance is the background clause (line 5) in which she uses 'there is' instead of target-like past simple 'there was' to signal past tense after temporal adverb 'at that time'. Another instance is found in Example (8), line 16 where the Indonesian participant switches to present verb 'come'; then in line 21 where she uses base forms 'stand up'. This may indicate a possible L1 transfer because, as I have presented in the literature review, Indonesian language relies heavily on temporal lexical adverbs, and not to morphological changes to indicate tense/aspect. However, this does not happen in Personal Narrative Task, line1, line 2, or line 4 (see Appendix 2) when she uses temporal adverbs.

This finding shows that there is an indication that she relies more on verbal morphology changes in the second task. The use of present and base forms is more prevalent in the direct quotations which are used more extensively in second task. In the second task, the Indonesian participant produces more direct quotations than that of the Minnesotan despite having lower word counts. This shows that the Indonesian participant's system in telling oral narrative is to use direct quotations extensively, which can be used to describe the background or to move the time frame as foreground clauses. On the contrary, in both tasks, the Minnesotan relies less on lexical temporal adverbs, and more on how she uses past simple. This is in line with Bardovi-Harlig's findings (2014) in her article in Interlanguage: Forty years later. The finding is that participant who is more often use appropriate past tense will rely more on tense/aspect rather than temporal adverbs. This also shows how lexical temporal adverbs play an important role in the Indonesian's interlanguage system when telling oral narratives. 


\section{CONCLUSIONS}

The findings of this study reveal that the tense/aspect used by the Indonesian participant in the oral narratives are different than that of the Minnesotan participant, who is a native American English speaker. Nevertheless, in the light of interlanguage paradigm, I should mention that the difference is more like a systematic language in use, rather than considered as errors or flaws that need to be fixed. This is suggested by how the Indonesian participant extensively uses quotative sentences in the second task, and how extensive the reliance on lexical temporal adverbial. The varieties of non-past used, such as base forms, present tense, or no verbs varieties are also accompanied by a cohesive device indicating continuity from the previous clause (which already past verbs) or temporal adverbials. This shows that relying on certain linguistic elements can still work for language learners when they make spontaneous meaning. The Indonesian participant in this study is an advanced learner, that is why she could produce utterances in past simple mostly in foregrounding. As a pedagogical implication, this brings me to think about intermediate learners who are still struggling with the use of past tense to create foregrounding clauses in narratives. Looking at the data in this study, I realize that learners can be made aware by doing text analysis to see the importance of either past tense or temporal adverbs to make their narratives of past events more understandable. Even when they are not in the stage to produce past simple in the foregrounding clause, we already give them tools to make their oral narratives more understandable, the lexical temporal adverbs.

This study is still limited in terms of member checking of data coding or analysis. Another person should check and code the data so there will be a rater's reliability. I might have missed something or misplaced a verb or other parts of speech. Another limitation is that the examples given in the study from the data are not extensive enough to be generalized. Therefore, this finding is a very specific case for both participants. The future research can explore more deeply into discourse analysis or detailed syntactical complexity of oral or written narratives produced by native or non-native speakers of English. Using corpora of students' narrative writing and comparing the developments of tense/aspect and temporal lexical adverbs can be very insightful as well.

\section{REFERENCES}

Anjarningsih, H.Y., \& Bastiaanse, R. (2011). Verbs and time reference in Standard Indonesian agrammatic speech. Aphasiology, 25 (12), 15621578. doi: http://dx.doi.org/10.1080/02687038.2011.626844

Bardovi-Harlig, K. (1995). A narrative perspective on the development of the tense/aspect system in second language acquisition. Studies in Second Language Acquisition Journal, 17, 263-291.

Bardovi-Harlig, K. (2014). Documenting interlanguage development. In Z. Han, \& E. Tarone, Interlanguage: Forty years later (pp. 127-146). Amsterdam: John Benjamins Publishing Company. 
Salaberry, M. R., \& Comajoan, L. (Eds.). (2013). Research design and methodology in studies on 12 tense and aspect. Boston: De Gruyter, Inc. Available from: ProQuest Ebook Central.

Collins, P. (2009). Language and Computers Ser.: Modals and Quasi-modals in English. Leiden, NL: Brill/Rodopi.

Chiravate, B. (2011). The role of narrative structure in the acquisition of English tense-aspect morphology by Thai learners. Journal of Pan-Pacific Association of Applied Linguistics 15(2), 27-43.

Han, Z., \& Tarone, E. (Eds.). (2014). Interlanguage: forty years later. Retrieved from https://ebookcentral.proquest.com

Selinker, L. (1972). Interlanguage. International Review of Applied Linguistics, 10, 209-231.

Selinker, L. (2014). Interlanguage 40 years on. In Han, Z., \& Tarone, E. (Eds.). (2014). Interlanguage: forty years later (pp. 229-263). Retrieved from https://ebookcentral.proquest.com 